\title{
Nanostructured Multilayer Composite Films of Manganese Dioxide/Nickel/Copper Sulfide Deposited on Polyethylene Terephthalate Supporting Substrate
}

\author{
Awangku Nabil Syafiq Bin Awangku Metosen, Suh Cem Pang, and Suk Fun Chin \\ Department of Chemistry, Faculty of Resource Science and Technology, Universiti Malaysia Sarawak, 94300 Kota Samarahan, \\ Sarawak, Malaysia \\ Correspondence should be addressed to Suh Cem Pang; suhcem@gmail.com
}

Received 23 January 2015; Accepted 29 March 2015

Academic Editor: Gaurav Mago

Copyright (C) 2015 Awangku Nabil Syafiq Bin Awangku Metosen et al. This is an open access article distributed under the Creative Commons Attribution License, which permits unrestricted use, distribution, and reproduction in any medium, provided the original work is properly cited.

\begin{abstract}
Nanostructured multilayer manganese dioxide/nickel/copper sulfide $\left(\mathrm{MnO}_{2} / \mathrm{Ni} / \mathrm{CuS}\right)$ composite films were successfully deposited onto supporting polyethylene terephthalate (PET) substrate through the sequential deposition of $\mathrm{CuS}, \mathrm{Ni}, \mathrm{and}_{\mathrm{MnO}}$ thin films by chemical bath deposition, electrodeposition, and horizontal submersion deposition techniques, respectively. Deposition of each thin-film layer was optimized by varying deposition parameters and conditions associated with specific deposition technique. Both $\mathrm{CuS}$ and $\mathrm{Ni}$ thin films were optimized for their electrical conductivity whereas $\mathrm{MnO}_{2}$ thin film was optimized for its microstructure and charge capacity. The electrochemical properties of nanostructured multilayer $\mathrm{MnO}_{2} / \mathrm{Ni} / \mathrm{CuS}$ composite films were evaluated by cyclic voltammetry as electrode materials of an electrochemical capacitor prototype in a dual-planar device configuration. Cyclic voltammogram in mild $\mathrm{Na}_{2} \mathrm{SO}_{4}$ aqueous electrolyte exhibited a featureless and almost rectangular shape which was indicative of the ideal capacitive behavior and high cycling reversibility of the electrochemical capacitor prototype. Nanostructured multilayer $\mathrm{MnO}_{2} / \mathrm{Ni} / \mathrm{CuS}$ composite films on supporting polyethylene terephthalate (PET) substrate could potentially be utilized as electrode materials for the fabrication of high performance electrochemical capacitors.
\end{abstract}

\section{Introduction}

Generally, the fabrication of thin-film electrochemical capacitor entails the deposition of an electroactive thin film onto an electrically conductive supporting substrate which serves collectively as both the current collector and the supporting substrate. A gel electrolyte layer which serves as the ionically conductive medium is subsequently added between the electrodes of electrochemical capacitor. Nanostructured manganese dioxide thin films have been comprehensively studied in recent years in order to determine the relations among their morphological, structural, and compositional characteristics for enhancing performance of electrochemical capacitors [1]. Methods commonly used for depositing nanostructured manganese dioxide thin films include anodic oxidation, electrodeposition, electroless deposition, successive ionic layer adsorption and reaction (SILAR), chemical bath deposition, electron beam evaporation, chemical vapor deposition, reactive sputtering, molecular beam epitaxy, pulsed layer deposition, and atomic layer deposition [2]. However, chemical deposition methods which involve growth from solution are more favorable as they are costeffective, and thin films of complex chemical compositions can be formed at low deposition temperature. Such low deposition temperature is highly desirable in order to avoid effects such as interdiffusion, contamination, and dopant redistribution. Besides, the morphology of thin films deposited can be easily controlled via optimizing preparative parameters. Unlike physical deposition methods, chemical deposition methods do not require high quality target or substrates nor do they require vacuum at any stage of deposition process [3]. The self-assembly horizontal submersion process and the electrophoretic deposition method have been demonstrated to be versatile and cost-effective deposition techniques for the 
deposition and optimization of nanoparticulate manganese dioxide thin films for the fabrication of electrochemical capacitors [4-6].

Nickel film is one of the main components in supercapacitors which serves as the electrical conductive current collector. Techniques used for preparing nickel film include thermal evaporation, spray pyrolysis, chemical vapor deposition, sol-gel, sputtering, chemical solution deposition, electroless deposition, and electrodeposition [7, 8]. However, electrodeposition is the most preferred technique because it is simple, economical, and faster, allows easier control on the thickness and uniformity of deposited films $[9,10]$, and is operable at normal room temperature. For the electrodeposition process, the chemical and physical properties of deposited films are influenced by the deposition conditions such as current density, deposition potential, bath composition, and electrolyte $\mathrm{pH}$ [4]. By varying the electrochemical deposition conditions, it is possible to control and optimize the particle size, surface morphology, crystallographic orientation, and mass, mechanical, electrical, magnetic, and magnetotransport properties of electrodeposited films [11, 12].

Deposition of copper sulfide thin films onto nonconductive polymeric materials has come into the limelight due to its wide range of applications in photothermal conversion, photovoltaic devices, selective solar-radiation filters, and electroconductive coatings for the deposition of metals [13, 14]. The depositions of $\mathrm{CuS}$ thin films on various polymeric surfaces reported include polyimide [15], polyethersulfone [16], polyethylene terephthalate (PET) [17], and ABS [18]. The deposition of CuS thin films onto PET substrate by the chemical bath deposition method is particularly advantageous due to its low temperature requirement, relatively simple setup, and low cost [17].

In this paper, we have reported the successful deposition of nanostructured multilayer manganese dioxide/nickel/ copper sulfide $\left(\mathrm{MnO}_{2} / \mathrm{Ni} / \mathrm{CuS}\right)$ composite films on supporting polyethylene terephthalate (PET) substrate through the sequential deposition of $\mathrm{CuS}, \mathrm{Ni}$, and $\mathrm{MnO}_{2}$ thin films by chemical bath deposition, electrodeposition, and self-assembly horizontal submersion deposition techniques, respectively. Factors that affect the initial deposition of $\mathrm{CuS}$ on the PET supporting substrate and subsequent electrodeposition of nickel thin films on CuS/PET substrate as well as the final deposition of nanoparticulate $\mathrm{MnO}_{2}$ thin films on the Ni/CuS/PET substrate via the novel horizontal submersion deposition technique were investigated. The CuS and nickel thin films were optimized for enhanced electrical conductivity whereas the nanoparticulate $\mathrm{MnO}_{2}$ thin film was optimized for enhanced charge capacity. The potential utility of multilayer $\mathrm{MnO}_{2} /$ nickel/CuS composite film on PET substrate as electrode materials for the fabrication of high-performance electrochemical capacitor was evaluated.

\section{Experiment}

2.1. Chemical Deposition of Copper Sulfide (CuS) Film on PET Substrate. The deposition of CuS film on PET substrate was conducted based on the method reported by Yamamoto et al. [19]. PET film with the dimensions of $1 \mathrm{~cm} \times 3 \mathrm{~cm}$ was immersed in a $1 \%$ methanol solution of polyethyleneimine (PEI) for 48 hours and then air-dried. The PEI treated PET was then immersed in a solution mixture of $0.1 \mathrm{M}$ copper sulfate $\left(\mathrm{CuSO}_{4} \cdot 5 \mathrm{H}_{2} \mathrm{O}\right)$ and $0.1 \mathrm{M}$ sodium thiosulphate $\left(\mathrm{Na}_{2} \mathrm{~S}_{2} \mathrm{O}_{3}\right)$ which was heated at $70-80^{\circ} \mathrm{C}$ and stirred for two hours to form CuS on PET film. Deposited CuS/PET composite films were heat treated at temperatures between 50 and $200^{\circ} \mathrm{C}$ in air for an hour using a tube furnace to optimize their electrical conductivity.

\subsection{Electrodeposition of Nickel Film onto CuS/PET Substrate.} The electrodeposition of nickel films on CuS/PET substrate was conducted in the Watts electrolyte based on the method reported by Badarulzaman et al. [20] using a standard 2-electrode cell configuration. The working and counter electrodes were being kept at a fixed distance of $1.0 \mathrm{~cm}$ and connected to a DC power supply (Model GPR-6030D). The applied potential was varied between 2.0 and 3.0 volts at a fixed deposition duration of 20 minutes, whereas the deposition duration was varied between 5 and 25 minutes at a fixed applied potential of 2.5 volts. Deposited Ni/CuS/PET composite films were heat treated at temperatures between 50 and $200^{\circ} \mathrm{C}$ in air for an hour using a tube furnace to optimize their electrical conductivity.

2.3. Deposition of $\mathrm{MnO}_{2}$ Thin Film on Ni/CuS/PET Substrate. Stable $\mathrm{MnO}_{2}$ colloidal suspension was prepared by the method reported by Perez-Benito et al. [21]. $\mathrm{MnO}_{2}$ thin film was deposited onto the $\mathrm{Ni} / \mathrm{CuS} / \mathrm{PET}$ substrate from the $\mathrm{MnO}_{2}$ colloidal suspension using the self-assembly horizontal submersion deposition technique [22]. The self-assembly horizontal submersion deposition technique entailed the initial ultrasonication of the $\mathrm{MnO}_{2}$ colloidal suspension for five minutes in order to enhance dispersion of nanoparticles. About $30 \mathrm{~mL}$ of $\mathrm{MnO}_{2}$ colloidal suspension was then used to fully submerge the $\mathrm{Ni} / \mathrm{CuS} / \mathrm{PET}$ supporting substrate which was being placed horizontally inside a Petri dish. After being submerged for 10 minutes, the excess $\mathrm{MnO}_{2}$ colloidal suspension was removed by siphoning.

The resulting $\mathrm{MnO}_{2} / \mathrm{Ni} / \mathrm{CuS} / \mathrm{PET}$ composite film was then air-dried overnight at room temperature and then heat treated at $200^{\circ} \mathrm{C}$ in air for an hour using a tube furnace to optimize its charge capacity. In this study, the heat treatment temperature was limited to $200^{\circ} \mathrm{C}$ or lower to prevent the degradation or disintegration of the polyethylene terephthalate (PET), which served as the supporting substrate.

\subsection{Characterization of CuS/PET, $\mathrm{Ni} / \mathrm{CuS} / \mathrm{PET}$, and $\mathrm{MnO}_{2} / \mathrm{Ni} /$} $\mathrm{CuS} / \mathrm{PET}$. The surface morphology and elemental composition of $\mathrm{CuS} / \mathrm{PET}, \mathrm{Ni} / \mathrm{CuS} / \mathrm{PET}$, and $\mathrm{MnO}_{2} / \mathrm{Ni} / \mathrm{CuS} / \mathrm{PET}$ films were studied using Scanning Electron Microscope (SEM) (JEOL JSM 6390LA) and Energy Dispersive X-Ray (EDX), respectively. The mean size of $\mathrm{CuS}$ and $\mathrm{Ni}$ particles was determined by measuring the diameters of about $50 \mathrm{Ni}$ particles randomly as observed in SEM micrographs using 


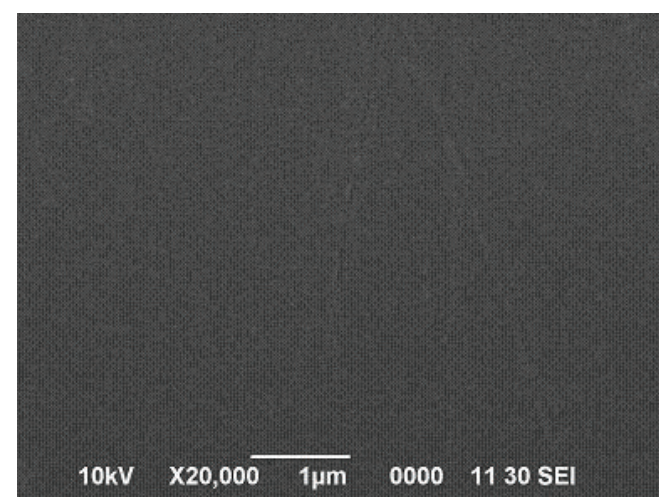

(a)

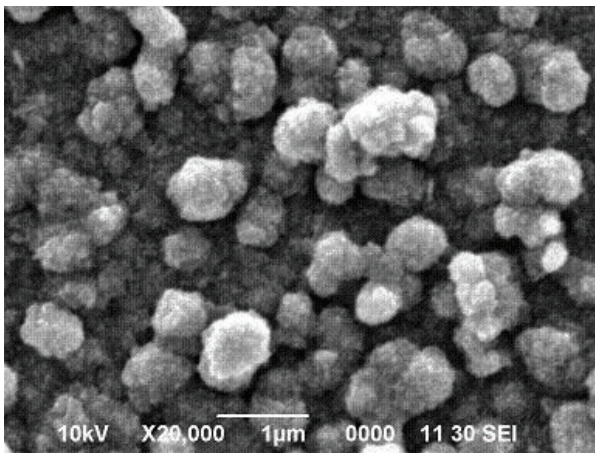

(c)

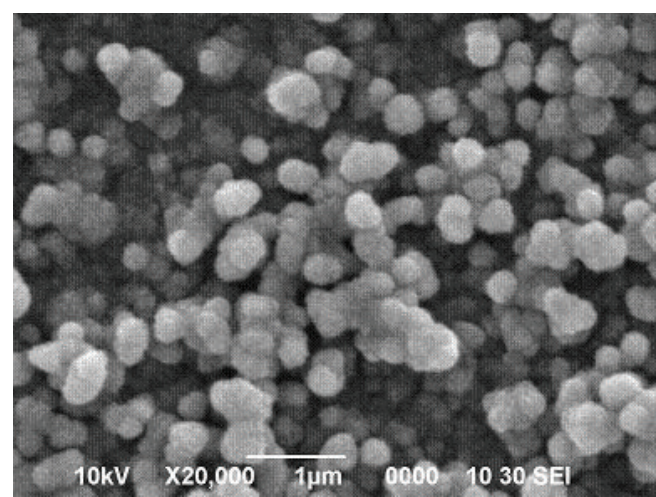

(b)

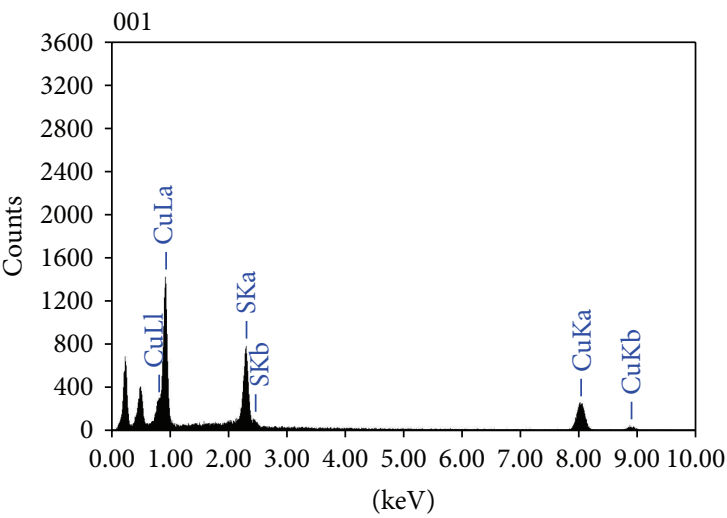

(d)

FIGURE 1: SEM micrographs of PEI treated PET film with number of copper sulphide (CuS) coatings: (a) 0, (b) 2, (c) 4, and (d) EDX spectra of CuS/PET film.

the JEOL SmileView software. A total of 3 SEM micrographs from 3 different samples of composite films were observed.

The sheet resistance of deposited films was measured based on the method reported by Nair et al. [16]. The surface resistance (sheet resistance) of deposited films was measured across a pair of silver electrodes of $10 \mathrm{~mm}$ in length and separated at $10 \mathrm{~mm}$ from each other as painted on the surface of the films. A hand-held digital multimeter was used for measuring the surface resistance of these films.

The electrochemical properties of $\mathrm{MnO}_{2}$ thin film deposited onto the Ni/CuS/PET substrate were determined by cyclic voltammetry with a computer interfaced potentiostat (Princeton Applied Research PARSTAT Model 2263). The capacitive behavior of electrochemical capacitor prototypes fabricated from dual-planar $\mathrm{MnO}_{2} / \mathrm{Ni} / \mathrm{CuS} / \mathrm{PET}$ electrodes with agar-based gel electrolytes film was evaluated.

\section{Results and Discussion}

3.1. Chemical Bath Deposition of Copper Sulfide (CuS) on PET Substrate. Upon submersion in a solution mixture of copper sulfate $\left(\mathrm{CuSO}_{4}\right)$ and sodium thiosulphate $\left(\mathrm{Na}_{2} \mathrm{~S}_{2} \mathrm{O}_{3}\right)$ at 70$80^{\circ} \mathrm{C}$, the color of PEI treated PET films was observed to change from transparent to brown and finally green after two hours, due to the deposition of a copper sulfide layer on the surfaces of PEI treated PET substrates. PEI acted as a binder/cross linker in order to enhance adherence of the CuS layer onto the PET supporting substrate.

PET substrates were coated with $\mathrm{CuS}$ film of varying thickness by repeating the chemical bath deposition processes with each deposited CuS layer air-dried in between. Figure 1 shows SEM micrographs of bare PET substrate and PET substrates deposited with varying number of $\mathrm{CuS}$ layers, as well as the EDX spectrum of $\mathrm{CuS}$ film deposited on the PET substrate. The surface morphology of PET substrate was observed to be smooth and featureless (Figure 1(a)). The deposition of thicker CuS film corresponded to the observed physical color change of PET substrate from light green to dark green color. PET substrates deposited with increasing number of $\mathrm{CuS}$ coatings showed spherical $\mathrm{CuS}$ particles of increasing mean diameters (Figures 1(b)-1(c)) which could be attributed to the "Ostwald ripening" process [17]. Further aggregation of CuS particles could have led to the formation of irregular particle clusters of varying sizes being deposited on the PET substrates. The mean particle sizes for deposited CuS films of 2 and 4 coatings were $299 \mathrm{~nm}$ and $684 \mathrm{~nm}$, respectively. As shown in Figure 1(d), the EDX spectrum revealed the presence of both copper and sulfur peaks indicating the successful deposition of $\mathrm{CuS}$ film onto the PEI treated PET substrate. Two additional peaks at about 
$0.2-0.3 \mathrm{keV}$ and at $0.5 \mathrm{keV}$ were attributed to carbon and oxygen atoms, respectively, originating from the PEI treated PET substrate.

\subsection{Electrodeposition of Nickel Film on CUS/PET Substrate.} Figure 2 shows the SEM micrographs of electrodeposited nickel films on CuS/PET substrates under different applied potentials at a fixed deposition duration of 20 minutes. Two coatings of $\mathrm{CuS}$ were deposited to ensure that CuS/PET of adequately high conductivity was obtained prior to subsequent electrodeposition of nickel films. Nickel films deposited at different applied potentials showed substantially different color. Nickel film deposited at potential of $2.0 \mathrm{~V}$ was observed to be dull gray in color whereas nickel films deposited at 2.5 and $3.0 \mathrm{~V}$ showed bright metallic gray color. Such difference in color could be attributed to the variation of nickel film thickness deposited on the CuS/PET substrates.

As shown in the SEM micrographs, all nickel films deposited at different applied potentials exhibited grainy and particulate surface morphology with different levels of compactness (Figure 2). Nickel film deposited at a lower applied potential of $2.0 \mathrm{~V}$ showed uniform but smaller mean particle aggregate size of $109 \mathrm{~nm}$ (Figure 2(a)) as compared to coarser particle aggregates with mean size of $671 \mathrm{~nm}$ for nickel film deposited at the applied potential of $3.0 \mathrm{~V}$ (Figure 2(c)). Based on Ohm's law, current is inversely proportional to applied potential. At lower applied potential, the higher current would enable more positively charged nickel divalent ions $\left(\mathrm{Ni}^{2+}\right)$ from the Watts electrolyte to be reduced into metallic nickel atoms and deposited on the surface of cathode. Agboola et al. [23] also stated that the amount of electrodeposited materials on the electrode surface is proportional to the deposition current applied during the electrodeposition process. Besides, changes in the surface morphological characteristic of nickel films could be induced by significant coevolution of hydrogen gas at the cathode at high applied deposition potential [24-26].

3.3. Effect of Electrodeposition Duration. The effect of electrodeposition duration on the surface morphology of deposited nickel film under a fixed applied potential is shown in Figure 3. Nickel films showed different surface morphologies with mean nickel particle sizes of $120 \mathrm{~nm}$ and $484 \mathrm{~nm}$ at the electrodeposition durations of 5 minutes and 25 minutes, respectively. Such difference in mean particle sizes and associated surface morphology of electrodeposited nickel films could be attributed to the nucleation and growth processes occurring during the electrodeposition process $[27,28]$. Initially, nickel nuclei of small mean sizes were deposited onto the copper sulfide layer. Upon prolonged electrodeposition, nucleation of nickel particles which covered the entire substrate became more rapid (Figure 3(b)). At even longer deposition times, coalescence of nickel particles and particle aggregation resulted in the formation of larger spherical particle clusters (Figure 3(c)). Longer deposition duration increased not only the density of nickel particles but also particle distribution over the surface of CuS/PET substrate. Nickel films of shiny metallic color were deposited at deposition durations of 20 and 25 minutes as compared to nickel films of dull grey color deposited at shorter deposition durations.

3.4. Effect of Surfactant. The effect of surfactant (sodium dodecyl sulfate, SDS) addition into the Watts electrolyte on electrodeposited nickel films is shown in Figure 4. Nickel film deposited on CuS/PET substrate without surfactant showed inhomogeneous agglomeration of nickel particles with a mean particle diameter of $352 \mathrm{~nm}$ (Figure 4(a)). In contrast, nickel films deposited in the presence of SDS $(1.0 \mathrm{~g} / \mathrm{L})$ exhibited more uniform and finer nickel particles with a mean particle diameter of $183 \mathrm{~nm}$ (Figure 4(b)). As the concentration of SDS was increased, the surface morphology of nickel film deposited on CuS/PET substrate showed higher homogeneity with more dispersed and uniformly distributed nickel particles of smaller mean sizes. The amphiphilic nature of SDS surfactant served as a wetting agent by altering the wettability of the CuS/PET substrate by reducing the surface tension of the electrolyte [29]. Electrolyte of lower surface tension would enhance the uniform dispersion of nickel particles on the substrate during electrodeposition. Farzaneh et al. [30] reported similar effect of SDS surfactant in electrolyte on the surface morphology of electrodeposited nickel films [30]. During electrodeposition of nickel film, evolution of hydrogen gas could occur as a by-product. Hydrogen gas, which normally caused pitting on the nickel film, could escape readily from the electrolyte solution in the presence of SDS surfactant due to its lower surface tension [31]. The addition of SDS surfactant (within the concentration range of 1.5 to $3.0 \mathrm{~g} / \mathrm{L}$ ) had therefore effectively minimized the pitting problem during electrodeposition by substantially reducing the number of pits formed on nickel film. In this study, the concentration range of SDS surfactant used was $0.0-3.0 \mathrm{~g} / \mathrm{L}$ and an optimum SDS concentration of $2.0 \mathrm{~g} / \mathrm{L}(6.9 \mathrm{mM})$ was determined for the electrodeposition of nickel films onto the $\mathrm{CuS} / \mathrm{PET}$ substrate. As such, the optimum SDS concentration was well below the critical micelle concentration (CMC) of SDS surfactant in pure water at $8.2 \mathrm{mM}$ [32].

3.5. Effect of Postdeposition Heat Treatment. Both nickel and copper sulfide films were subjected to postdeposition heat treatment in order to enhance their surface morphology and adherence to the PET substrate and CuS film, respectively [33]. Figure 5 shows the surface morphology of CuS film on PET substrate and nickel film on CuS/PET substrate after being heat treated in air at various temperatures.

The surface morphology of copper sulfide film showed significant changes upon being heated in air at $150^{\circ} \mathrm{C}$ (Figures 5(a) and 5(b)). Copper sulfide film without heating showed comparatively larger particle sizes within the range of 125$232 \mathrm{~nm}$, whereas film heat treated in air at $150^{\circ} \mathrm{C}$ showed uniform aggregates of smaller particle sizes within the range of $76-105 \mathrm{~nm}$. In this study, the maximum heating temperature was limited to $200^{\circ} \mathrm{C}$ in order to avoid degradation of the PET supporting substrate.

The surface morphology of nickel films deposited on $\mathrm{CuS} / \mathrm{PET}$ substrate was observed to have altered substantially 


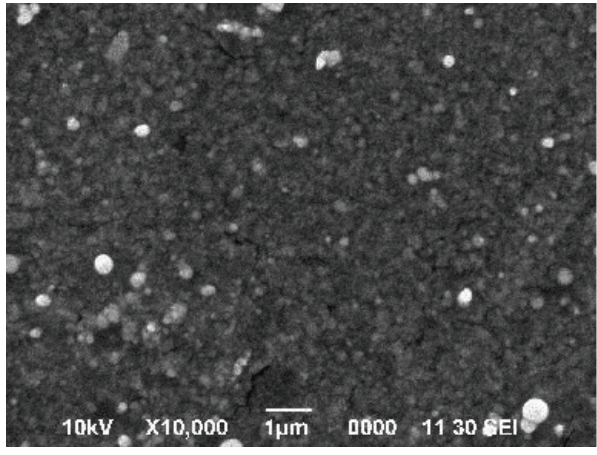

(a)

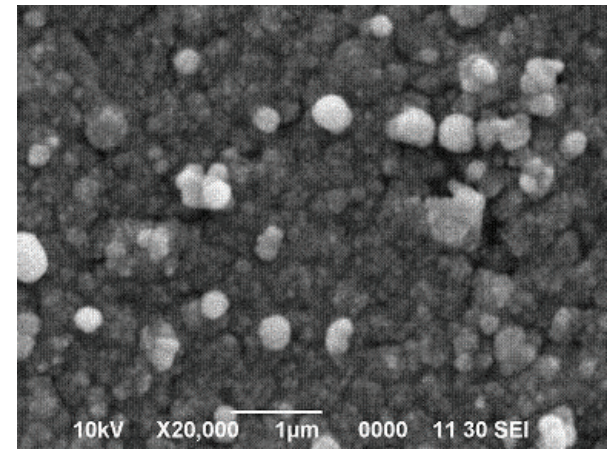

(b)

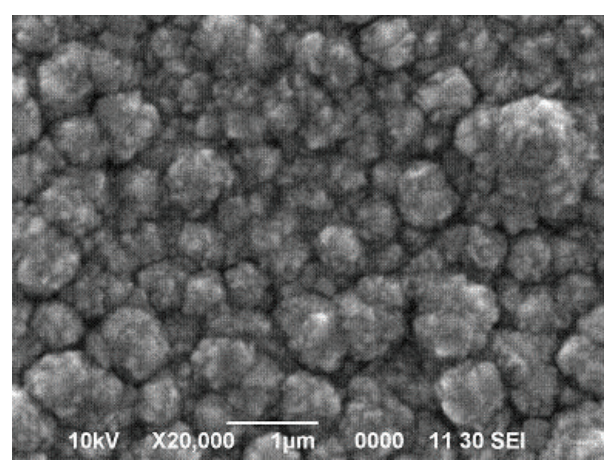

(c)

FIGURE 2: SEM micrographs of nickel films electrodeposited on CuS/PET substrates under different applied potentials: (a) $2.0 \mathrm{~V}$, (b) $2.5 \mathrm{~V}$, and (c) $3.0 \mathrm{~V}$.

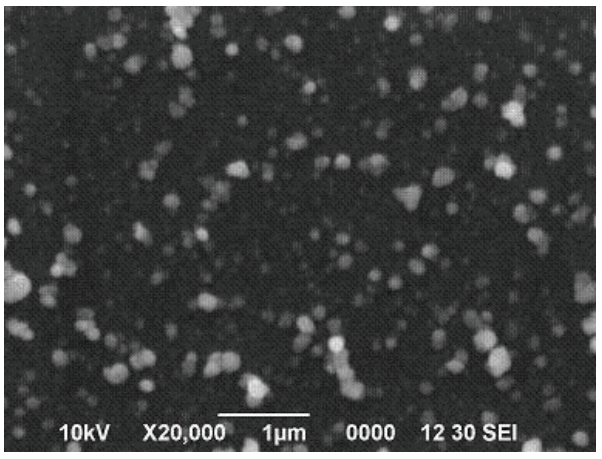

(a)

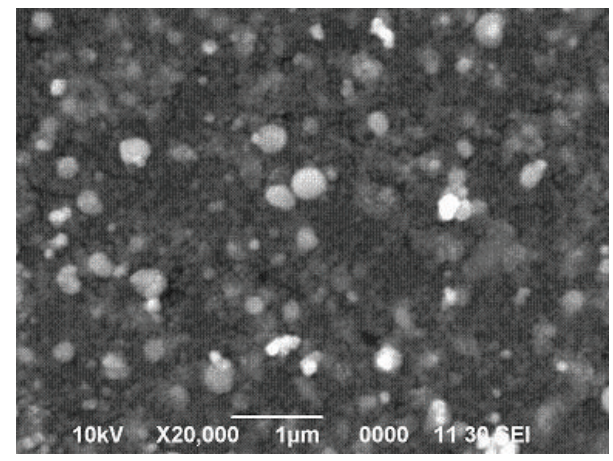

(b)

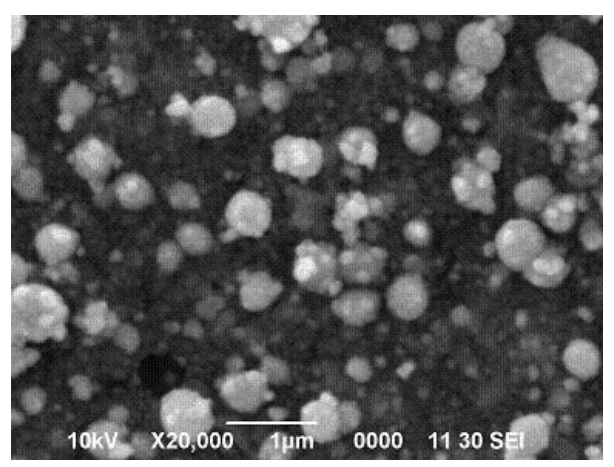

(c)

FIGURE 3: SEM micrographs of nickel films electrodeposited on CuS/PET substrate for different durations: (a) 5 minutes, (b) 10 minutes, and (c) 25 minutes. 


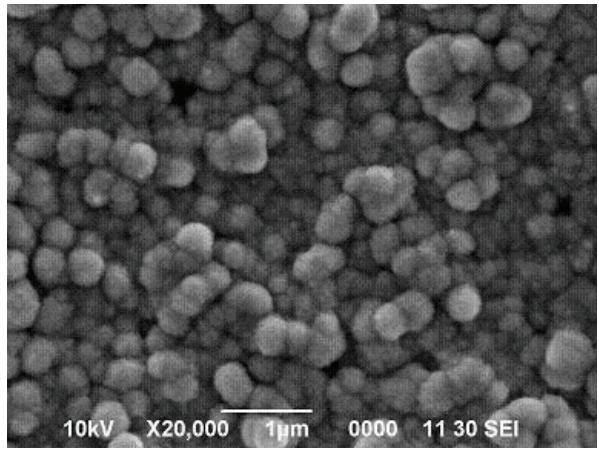

(a)

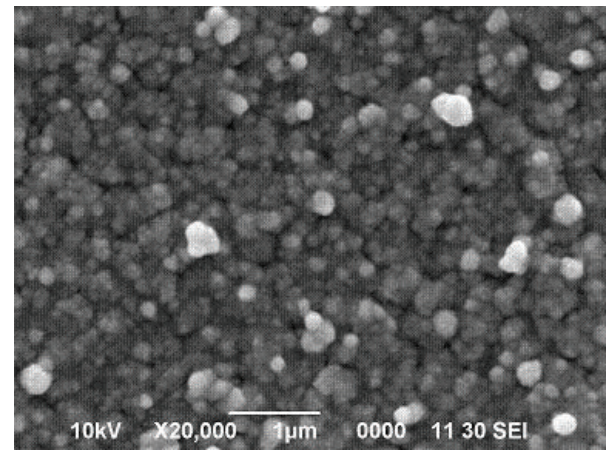

(b)

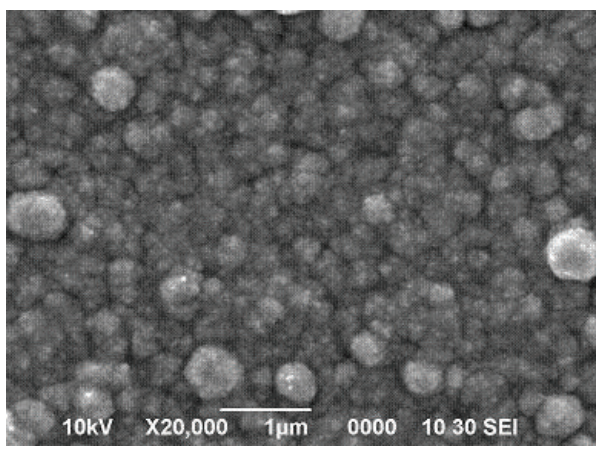

(c)

FIGURE 4: SEM micrographs of Ni/CuS/PET substrate with nickel film deposited in the presence of different concentrations (g/L) of SDS surfactant in the Watts electrolyte: (a) 0 , (b) 1.0 , and (c) 2.0 .

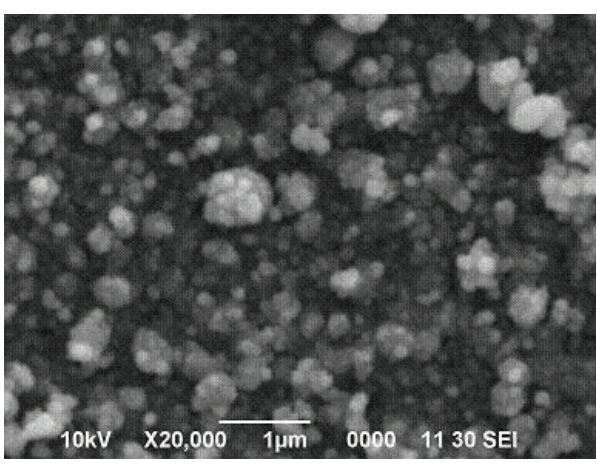

(a)

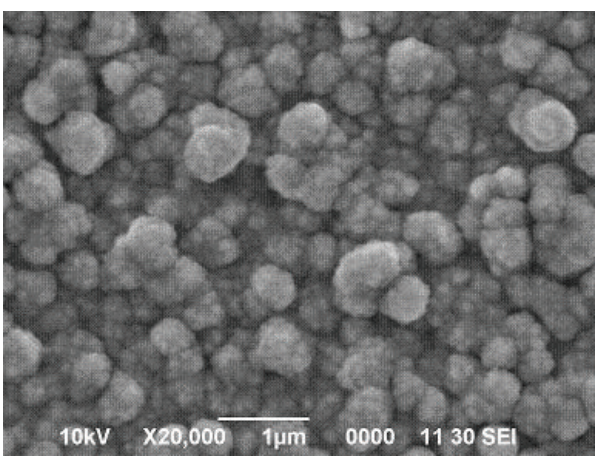

(c)

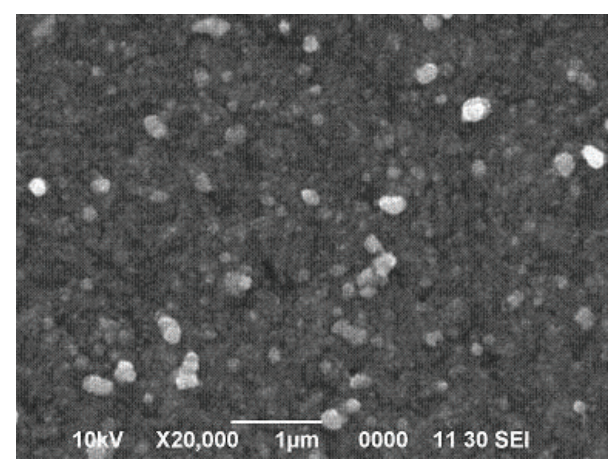

(b)

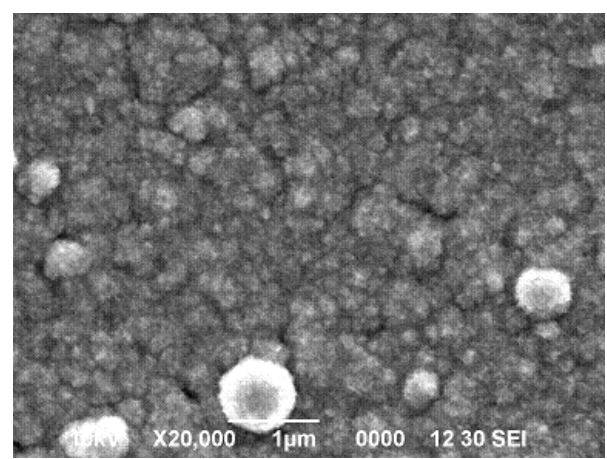

(d)

Figure 5: SEM micrographs of CuS/PET substrates: (a) without heating and (b) heat treated at $150^{\circ} \mathrm{C}$, and Ni/CuS/PET substrate after heat treatment at different temperatures: (c) $50^{\circ} \mathrm{C}$ and (d) $200^{\circ} \mathrm{C}$. 


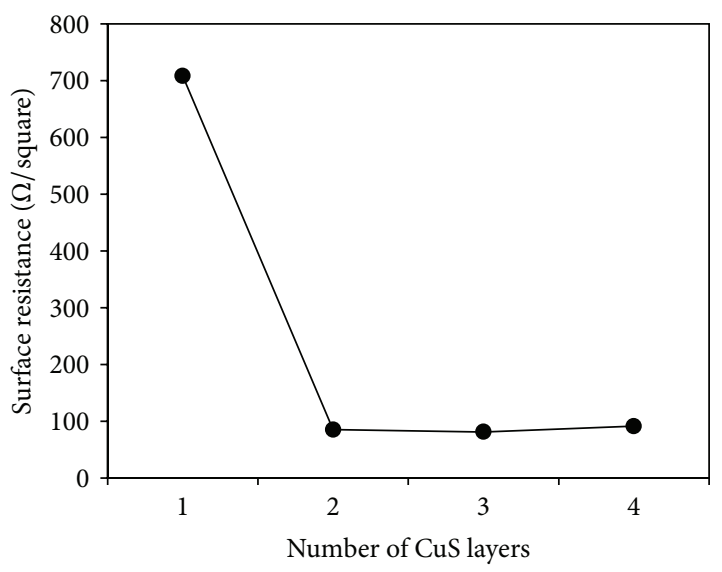

(a)

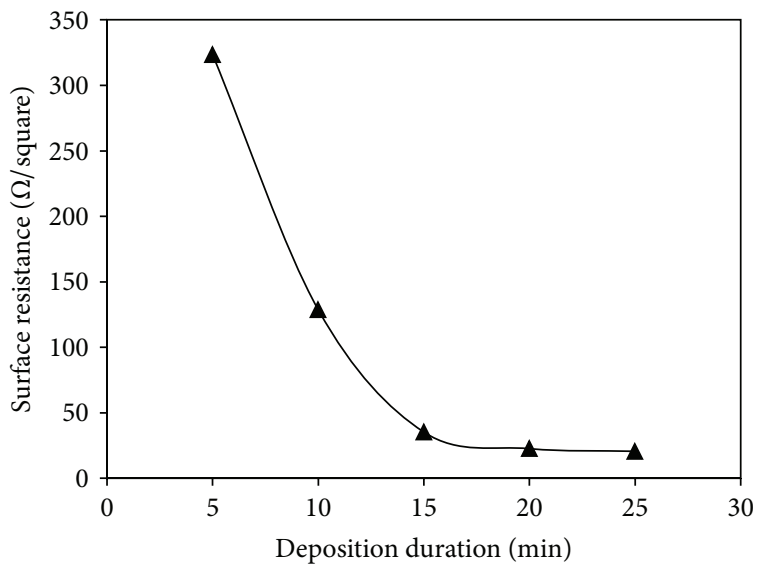

(c)

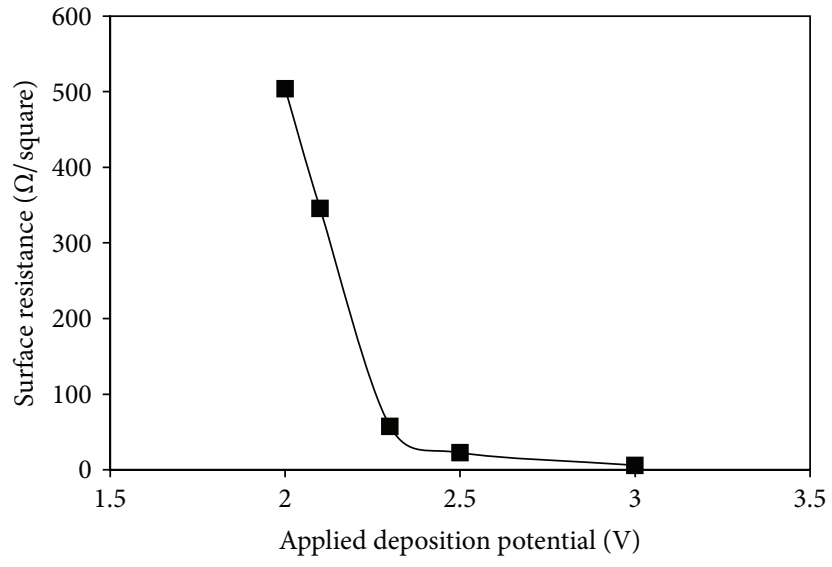

(b)

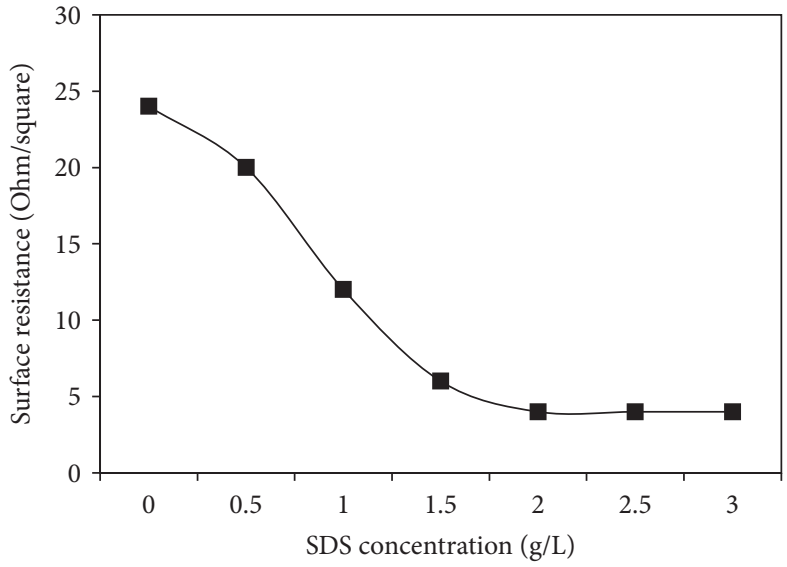

(d)

FIGURE 6: Relative surface resistivity of deposited films under different deposition conditions: (a) effect of number of CuS coatings, (b) effect of applied deposition potential for nickel film, (c) effect of deposition duration for nickel film, and (d) effect of SDS concentration for nickel film.

upon being heat treated in air at different temperatures of $50^{\circ} \mathrm{C}$ and $200^{\circ} \mathrm{C}$ (Figures 5(c)-5(d)). Upon heat treatment at $200^{\circ} \mathrm{C}$, nickel particles were of substantially smaller mean size and nanowhiskers or dendrite-like structures were formed on the surface of nickel particles. Such morphological changes could be induced by the loss of hydrated water from the nickel film [34].

3.6. Effect of Deposition Conditions. Figure 6 shows the effect of deposition conditions on the relative surface resistivity of $\mathrm{CuS}$ and nickel films. As shown in Figure 6(a), thicker $\mathrm{CuS}$ films of 2 coatings showed substantially lower relative surface resistivity ( $81 \Omega$ /square) than that of thinner film of a single coating (708 $\Omega$ /square). However, no further notable decrease in the surface resistivity was observed for thicker $\mathrm{CuS}$ films of more than 2 coatings. The reduced surface resistivity of thicker $\mathrm{CuS}$ films could be attributed to enhanced interconnectivity between larger $\mathrm{CuS}$ particles, as well as higher film homogeneity and density which collectively resulted in lower resistance to current flow [35].

The effect of applied potential on the relative surface resistivity of nickel film on CuS/PET substrate is shown in
Figure $6(\mathrm{~b})$. The relative surface resistivity of nickel film on CuS/PET substrate was substantially lower at higher applied potential; in addition, nickel film deposited at applied potentials of $3.0 \mathrm{~V}$ and $2.0 \mathrm{~V}$ exhibited surface resistivity of $6 \Omega$ /square and $500 \Omega$ /square, respectively. Such variations in the surface resistivity of nickel films could be attributed to the relative compactness of nickel particles within these films. The more compact granular microstructure of nickel film deposited at the applied potential of $3.0 \mathrm{~V}$ had resulted in higher electrical conductivity (Figure 6(b)). The electrical conductivity of a given material is influenced by the formation of continuous network chains of conductive particles and is dependent on the number of contacts that each particle makes with its adjacent particles [36].

The relative surface resistivity of nickel films deposited on $\mathrm{CuS} / \mathrm{PET}$ substrate was observed to decrease rapidly with increasing electrodeposition duration (Figure 6(c)). The relative surface resistivity of nickel films deposited on CuS/PET substrate at deposition durations of 5 and 25 minutes was $323 \Omega$ /square and $21 \Omega$ /square, respectively. The observed variation of relative surface resistivity could be attributed 
to both the thickness and the surface morphology of nickel films (Figure 3). Thicker nickel films with larger particle sizes were found to exhibit substantially lower relative surface resistivity (higher electrical conductivity) as compared to thinner nickel films with smaller particle size. Larger nickel particles provided better electrical contacts between adjacent particles with enhanced electrons movement and hence lower resistance. Similar effect of nickel particle sizes on the resistance of electroplated nickel films had been reported [37].

Figure 6(d) shows the variation of surface resistivity of nickel films deposited on CuS/PET substrate in the presence of various SDS concentrations in the Watts electrolyte. The relative surface resistivity of nickel film was observed to decrease gradually as the SDS concentration was increased up to $2.0 \mathrm{~g} / \mathrm{L}$. The relative surface resistivity of nickel film deposited on CuS/PET decreased from $24 \Omega$ /square without SDS to about $4 \Omega /$ square in the presence of $2.0 \mathrm{~g} / \mathrm{L} \mathrm{SDS}$ in the Watts electrolyte. However, no further reduction in the relative surface resistivity of nickel film was observed for the concentration of above $2.0 \mathrm{~g} / \mathrm{L}$ SDS in the Watts electrolyte. The observed decrease in relative surface resistivity could be attributed to changes in the microstructural morphology of nickel films deposited from agglomerated and inhomogeneous surface morphology into a more compact and uniform surface morphology (Figures 4(b) and 4(c)). Besides, addition of higher amount of SDS into the Watts electrolyte could have enabled more effective dispersion of nickel colloidal particles generated through the reduction of nickel ions during electrodeposition process which, in turn, led to the deposition of nickel film that was more compact. Surfactant affects the electrodeposition process by modifying the dispersion/aggregation state of the colloidal particles [38]. Electrostatic interactions between surfactant molecules and nickel ions could have substantial influence on the size of colloidal nickel particles generated during the electrodeposition process. Besides, at optimum SDS concentration, the contact angle would be reduced and led to better wettability of the CuS/PET substrate and hence the deposition of nickel film of more compact and uniform morphology.

A uniform and compact surface morphology of nickel film would provide unimpeded pathway for the flow of electrons between nickel particles, thus resulting in lower electrical resistance of films. Addition of higher SDS concentration $(>2.0 \mathrm{~g} / \mathrm{L})$ into the Watts solution had no observable influence on the surface resistivity of nickel film, which had remained constant at $4 \Omega /$ square. Hence, $2.0 \mathrm{~g} / \mathrm{L}$ of SDS was considered as the optimum SDS concentration for the electrodeposition of nickel films onto CuS/PET substrates.

Figure 7 shows the effect of heat treatment temperatures on the relative surface resistivity of $\mathrm{CuS}$ film and $\mathrm{Ni} / \mathrm{CuS}$ composite film deposited on PET supporting substrate after being heat treated in air at various temperatures for two hours. Heat treatment temperatures showed distinctive influence on both surface resistance and surface morphology of both $\mathrm{CuS}$ and $\mathrm{Ni} / \mathrm{CuS}$ composite films which demonstrated substantially lower surface resistances after being heat

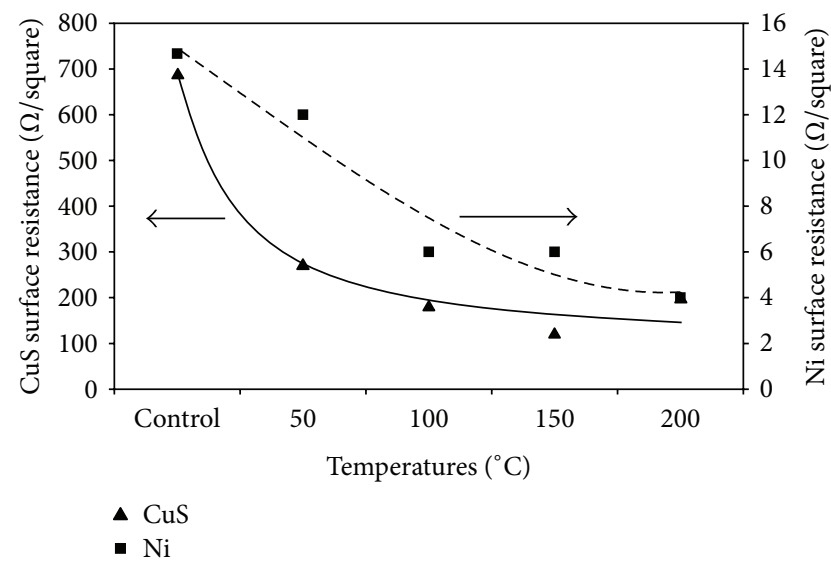

FIGURE 7: Effect of heat treatment temperatures on the relative surface resistivity of $\mathrm{CuS}$ film and $\mathrm{Ni} / \mathrm{CuS}$ composite film deposited on PET supporting substrate (two coatings of CuS; Ni film deposition conditions: applied potential $2.5 \mathrm{~V}$; duration of 25 minutes; addition of $2.0 \mathrm{~g} / \mathrm{L} \mathrm{SDS}$ ).

treated at various temperatures. This could be attributed to substantial densification of both types of films which comprised uniform particles of relatively smaller sizes after heat treatment (Figure 5). The refinement of particle structures would result in significant number of nickel particles being incorporated into the particle boundaries, thus yielding the compact morphology [39]. Compact arrangement of smallsized particles leads to reduced interparticle spaces between adjacent nickel particles. Besides, annihilation of nickel grain boundaries during thermally activated process can lead to decrease in the resistivity of the nickel film [40]. Similar effects of annealing temperatures on mean particle sizes and surface resistance of nickel films have been reported [34]. The lowest surface resistivity for nickel and copper sulfide films was $4 \Omega$ /square and $159 \Omega$ /square after being heat treated at $200^{\circ} \mathrm{C}$ and $150^{\circ} \mathrm{C}$, respectively.

Qualitative adherence tests were performed using normal Scotch sticking tape for both $\mathrm{CuS}$ and $\mathrm{Ni} / \mathrm{CuS}$ films deposited on PET substrates. The sticking tape was initially being pressed firmly onto the surfaces of $\mathrm{CuS}$ and $\mathrm{Ni} / \mathrm{CuS}$ films and was subsequent pulled abruptly. Both films had remained intact on the PET substrate, indicating good adherence between both $\mathrm{Ni}$ and $\mathrm{CuS}$ films and between the $\mathrm{CuS}$ film and PET supporting substrate.

3.7. Characterization of $\mathrm{MnO}_{2} / \mathrm{Ni} / \mathrm{CuS} / \mathrm{PET}$ Composite Film. Figure 8 shows the SEM micrograph of $\mathrm{MnO}_{2}$ film deposited on the as-prepared $\mathrm{Ni} / \mathrm{CuS} / \mathrm{PET}$ substrate using the selfassembly horizontal submersion technique and the capacitive behavior of nanostructured multilayer $\mathrm{MnO}_{2} / \mathrm{Ni} / \mathrm{CuS}$ composite film on PET supporting substrate. The $\mathrm{MnO}_{2}$ film was deposited as a dark brown layer on the $\mathrm{Ni} / \mathrm{CuS} / \mathrm{PET}$ substrate without the aid of any binder. However, the SEM micrograph depicted the presence of cracks on the surface morphology of $\mathrm{MnO}_{2}$ film which could be attributed to the densification of $\mathrm{MnO}_{2}$ film upon heat treatment at $200^{\circ} \mathrm{C}$. TEM micrographs 


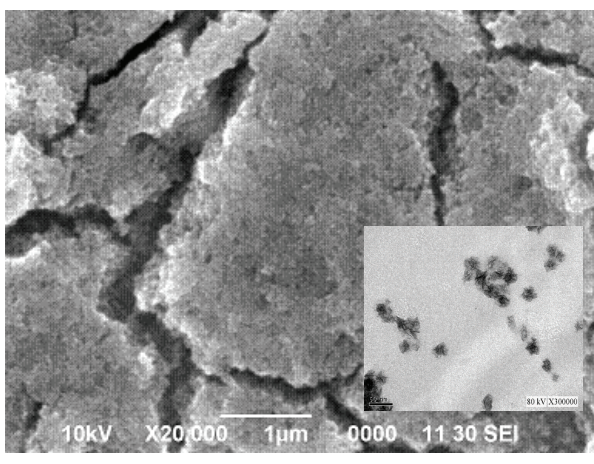

(a)

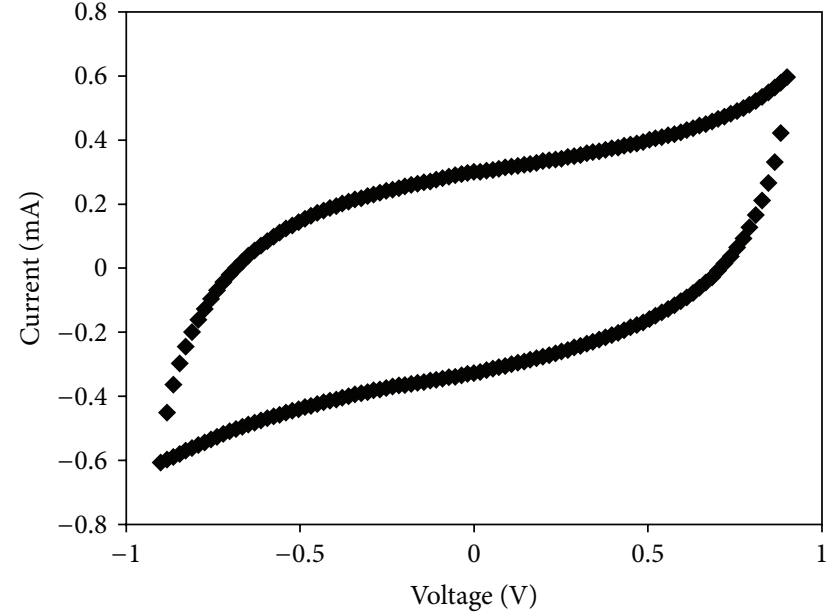

(b)

FIGURE 8: (a) SEM micrograph of $\mathrm{MnO}_{2}$ film deposited onto the Ni/CuS/PET substrate; inset shows TEM micrograph of $\mathrm{MnO}_{2}$ nanoparticles; (b) cyclic voltammetry of supercapacitor prototypes fabricated with multilayer $\mathrm{MnO}_{2} / \mathrm{Ni} / \mathrm{CuS}$ composite film on PET supporting substrate.

of $\mathrm{MnO}_{2}$ indicated the nanoparticulate nature of deposited $\mathrm{MnO}_{2}$ film (Figure 8(a)).

Figure 8(b) shows the $\mathrm{CV}$ curve of a $\mathrm{MnO}_{2} / \mathrm{Ni} / \mathrm{CuS} / \mathrm{PET}$ supercapacitor prototype in $0.2 \mathrm{M} \mathrm{Na}_{2} \mathrm{SO}_{4}$ aqueous electrolyte within a potential range of -0.9 to $+0.9 \mathrm{~V}$ at a scan rate of $50 \mathrm{mV} / \mathrm{s}$. The supercapacitor prototype was fabricated from two identical $\mathrm{MnO}_{2} / \mathrm{Ni} / \mathrm{CuS} / \mathrm{PET}$ electrodes in a dual-planar configuration. The almost rectangular $\mathrm{CV}$ profile indicated that the prototype exhibited ideal capacitive behavior. In addition, no oxidation and reduction (redox) peaks were observed within the scan potential range, indicating that the nanostructured multilayer $\mathrm{MnO}_{2} / \mathrm{Ni} / \mathrm{CuS} / \mathrm{PET}$ composite electrodes were stable and highly reversible [41]. The overall charge capacity of the supercapacitor prototype was determined to be about $16 \mathrm{mF} / \mathrm{cm}^{2}$. The sequential multilayer deposition process for the deposition of nanostructured multilayer $\mathrm{MnO}_{2} / \mathrm{Ni} / \mathrm{CuS}$ composite film could be further optimized in order to enhance the electrical conductivity of both the nickel and CuS films as well as the charge capacity of electroactive nanoparticulate $\mathrm{MnO}_{2}$ films.

\section{Conclusion}

Multilayer $\mathrm{MnO}_{2} / \mathrm{Ni} / \mathrm{CuS}$ composite films were successfully deposited on PET supporting substrate through the sequential deposition of $\mathrm{CuS}, \mathrm{Ni}$, and $\mathrm{MnO}_{2}$ thin films on PET supporting substrate using chemical bath deposition, electrodeposition, and horizontal submersion techniques, respectively. Deposition of thin-film layer was optimized by optimizing deposition parameters and conditions associated with each of the deposition techniques. Both $\mathrm{CuS}$ and $\mathrm{Ni}$ thin films were optimized for their electrical conductivity and the $\mathrm{MnO}_{2}$ thin film was optimized for its charge capacity or specific capacitances. The capacitive behaviors of multilayer $\mathrm{MnO}_{2} / \mathrm{Ni} / \mathrm{CuS}$ on PET supporting substrate were evaluated by cyclic voltammetry as electrode of a dual-planar electrochemical capacitor prototype. The electrochemical capacitor exhibits almost rectangular shaped voltammogram indicating ideal capacitive behavior and excellent reversibility albeit substantial capacitance fading observed upon long term cycling. Further optimization of sequential multilayer deposition process is necessary to enhance the electrical conductivity of the $\mathrm{Ni} / \mathrm{CuS}$ layer as well as microstructural control of electroactive nanoparticulate $\mathrm{MnO}_{2}$ films.

\section{Disclosure}

The authors of this paper have no direct financial relation with the commercial entities mentioned in this paper.

\section{Conflict of Interests}

The authors declare that there is no conflict of interests regarding the publication of the paper.

\section{Acknowledgments}

The authors gratefully acknowledge the financial support by the Malaysian Ministry of Science Technology and Innovation (MOSTI) rendered through the Award of Science Fund (03-01-09-SF0076), as well as research management and support services provided by the Research Innovation and Management Centre (RIMC), Universiti Malaysia Sarawak (UNIMAS).

\section{References}

[1] P. Staiti and F. Lufrano, "Study and optimisation of manganese oxide-based electrodes for electrochemical supercapacitors," Journal of Power Sources, vol. 187, no. 1, pp. 284-289, 2009.

[2] O. Nilsen, H. Fjellvåg, and A. Kjekshus, "Growth of manganese oxide thin films by atomic layer deposition," Thin Solid Films, vol. 444, no. 1-2, pp. 44-51, 2003. 
[3] C. D. Lokhande, D. P. Dubal, and O.-S. Joo, "Metal oxide thin film based supercapacitors," Current Applied Physics, vol. 11, no. 3, pp. 255-270, 2011.

[4] M.-S. Wu, C.-Y. Huang, and K.-H. Lin, "Electrophoretic deposition of nickel oxide electrode for high-rate electrochemical capacitors," Journal of Power Sources, vol. 186, no. 2, pp. 557-564, 2009.

[5] S. C. Pang, B. H. Wee, and S. F. Chin, "The capacitive behavior of manganese dioxide thin films electrochemical capacitor prototypes," International Journal of Electrochemistry, vol. 2011, Article ID 397685, 10 pages, 2011.

[6] S. C. Pang, S. F. Chin, and C. Y. Ling, "Preparation and characterization of self-assembled manganese dioxide thin films," Journal of Nanotechnology, vol. 2011, Article ID 789305, 7 pages, 2011.

[7] P. S. Patil and L. D. Kadam, "Preparation and characterization of spray pyrolyzed nickel oxide (NiO) thin films," Applied Surface Science, vol. 199, no. 1-4, pp. 211-221, 2002.

[8] B. Pejova, T. Kocareva, M. Najdoski, and I. Grozdanov, "Solution growth route to nanocrystalline nickel oxide thin films," Applied Surface Science, vol. 165, no. 4, pp. 271-278, 2000.

[9] K. Tanakaa, M. Sakakibara, and H. Kimachi, "Grain-size effect on fatigue properties of nanocrystalline nickel thin films made by electrodeposition," Procedia Engineering, vol. 10, pp. 542-547, 2011.

[10] A. Zoikis-Karathanasis, E. A. Pavlatou, and N. Spyrellis, "The effect of heat treatment on the structure and hardness of pulse electrodeposited NiP-WC composite coatings," Electrochimica Acta, vol. 54, no. 9, pp. 2563-2570, 2009.

[11] M. Alper, H. Kockar, M. Safak, and M. C. Baykul, "Comparison of Ni-Cu alloy films electrodeposited at low and high pH levels," Journal of Alloys and Compounds, vol. 453, no. 1-2, pp. 15-19, 2008.

[12] U. S. Mohanty, "Electrodeposition: a versatile and inexpensive tool for the synthesis of nanoparticles, nanorods, nanowires, and nanoclusters of metals," Journal of Applied Electrochemistry, vol. 41, no. 3, pp. 257-270, 2011.

[13] L. Isac, I. Popovici, and A. Duta, "Tailoring chemically sprayed CuXS films crystallinity," Revue Roumaine de Chimie, vol. 56, no. 12, pp. 1107-1112, 2011.

[14] V. Janickis, R. Maciulevičiuse, R. Ivanauskas, and I. Ancutiene, "Chemical deposition of copper sulfide films in the surface of polyamide by the use of higher polythionic acids," Colloid and Polymer Science, vol. 281, no. 1, pp. 84-89, 2003.

[15] J. Cardoso, O. G. Daza, L. Ixtlilco, M. T. S. Nair, and P. K. Nair, "Conductive copper sulfide thin films on polyimide foils," Semiconductor Science and Technology, vol. 16, no. 2, pp. 123-127, 2001.

[16] P. K. Nair, J. Cardoso, O. G. Daza, and M. T. S. Nair, "Polyethersulfone foils as stable transparent substrates for conductive copper sulfide thin film coatings," Thin Solid Films, vol. 401, no. 1-2, pp. 243-250, 2001.

[17] M. H. Kunita, E. M. Girotto, E. Radovanovic et al., "Deposition of copper sulfide on modified low-density polyethylene surface: morphology and electrical characterization," Applied Surface Science, vol. 202, no. 3-4, pp. 223-231, 2002.

[18] V. Popescu and H. I. Naşcu, "Electrical properties of plastic/ CuxS/Ni composites," Journal of Optoelectronics and Advanced Materials, vol. 8, no. 5, pp. 1874-1878, 2006.

[19] T. Yamamoto, K. Tanaka, E. Kubota, and K. Osakada, "Deposition of copper sulfide on the surface of poly(ethylene terephthalate) and poly(vinyl alcohol) films in the aqueous solution to give electrically conductive films," Chemistry of Materials, vol. 5, no. 9, pp. 1352-1357, 1993.

[20] N. A. Badarulzaman, A. A. Mohamad, S. Puwadaria, and Z. A. Ahmad, "The evaluation of nickel deposit obtained via Watts electrolyte at ambient temperature," Journal of Coatings Technology Research, vol. 7, no. 6, pp. 815-820, 2010.

[21] J. F. Perez-Benito, C. Arias, and E. Amat, "A kinetic study of the reduction of colloidal manganese dioxide by oxalic acid," Journal of Colloid and Interface Science, vol. 177, no. 2, pp. 288297, 1996

[22] S. C. Pang and B. H. Wee, "Flexible Thin Film Supercapacitor and Method of Fabrication Thereof," Malaysian Patent: MY151010-A, 2014.

[23] O. S. Agboola, E. R. Sadiku, and O. F. Biotidara, "The properties and the effect of operating parameters on nickel plating," International Journal of the Physical Sciences, vol. 7, no. 3, pp. 349-360, 2012.

[24] J. L. Hudson and T. T. Tsotsis, "Electrochemical reaction dynamics: a review," Chemical Engineering Science, vol. 49, no. 10, pp. 1493-1572, 1994.

[25] F. Lantelme, A. Seghiouer, and A. Derja, "Model of nickel electrodeposition from acidic medium," Journal of Applied Electrochemistry, vol. 28, no. 9, pp. 907-913, 1998.

[26] U. Sarac, R. M. Öksüzoĝlu, and M. C. Baykul, "Deposition potential dependence of composition, microstructure, and surface morphology of electrodeposited Ni-Cu alloy films," Journal of Materials Science: Materials in Electronics, vol. 23, no. 12, pp. 2110-2116, 2012.

[27] R. H. Guo, S. Q. Jiang, C. W. M. Yuen, M. C. F. Ng, and G. H. Zheng, "Influence of nickel ions for electroless Ni-P plating on polyester Fabric," Journal of Coatings Technology Research, vol. 9, no. 2, pp. 171-176, 2012.

[28] G. T. Martínez, G. Zavala, and M. Videa, "Electrodeposition of nickel particles and their characterization," Journal of the Mexican Chemical Society, vol. 53, no. 1, pp. 7-11, 2009.

[29] D. S. Dalavi, M. J. Suryavanshi, S. S. Mali, D. S. Patil, and P. S. Patil, "Efficient maximization of coloration by modification in morphology of electrodeposited $\mathrm{NiO}$ thin films prepared with different surfactants," Journal of Solid State Electrochemistry, vol. 16, no. 1, pp. 253-263, 2012.

[30] A. Farzaneh, M. Ehteshamzadeh, M. Ghorbani, and J. V. Mehrabani, "Investigation and optimization of SDS and key parameters effect on the nickel electroless coatings properties by Taguchi method," Journal of Coatings Technology Research, vol. 7, no. 5, pp. 547-555, 2010.

[31] J. Lu, Q.-H. Yang, and Z. Zhang, "Effects of additives on nickel electrowinning from sulfate system," Transactions of Nonferrous Metals Society of China, vol. 20, supplement 1, pp. s97-s101, 2010.

[32] P. Mukerjee and K. J. Mysels, CMC of Aqueous Surfactant Systems, NSRDS-NBS 36, US Government Printing Office, Washington, DC, USA, 1971.

[33] A. I. Inamdar, Y. Kim, S. M. Pawar, J. H. Kim, H. Im, and H. Kim, "Chemically grown, porous, nickel oxide thin-film for electrochemical supercapacitors," Journal of Power Sources, vol. 196, no. 4, pp. 2393-2397, 2011.

[34] M.-S. Wu and H.-H. Hsieh, "Nickel oxide/hydroxide nanoplatelets synthesized by chemical precipitation for electrochemical capacitors," Electrochimica Acta, vol. 53, no. 8, pp. 34273435, 2008. 
[35] J. Wu and D. D. L. Chung, "Combined use of magnetic and electrically conductive fillers in a polymer matrix for electromagnetic interference shielding," Journal of Electronic Materials, vol. 37, no. 8, pp. 1088-1094, 2008.

[36] E. Sancaktar and L. Bai, "Electrically conductive epoxy adhesives," Polymers, vol. 3, no. 4, pp. 427-466, 2011.

[37] J. K. Luo, M. Pritschow, A. J. Flewitt, S. M. Spearing, N. A. Fleck, and W. I. Milne, "Effects of process conditions on properties of electroplated $\mathrm{Ni}$ thin films for microsystem applications," Journal of the Electrochemical Society, vol. 153, no. 10, pp. D155D161, 2006.

[38] C. Filiatre, L. Towarnicki, F. Mange, and A. Foissy, "Parallel plate flow cell for the investigation of the role of surfactants in the codeposition of polymer particles in nickel electroplating," Journal of Applied Electrochemistry, vol. 29, no. 12, pp. 1393$1400,1999$.

[39] S. Graham, J. Kelley, N. Yang, and T. Borca-Tasciuc, "The role of microstructure in the electrical and thermal conductivity of $\mathrm{Ni}$ alloys for LIGA microsystems," Microsystem Technologies, vol. 10, no. 6-7, pp. 510-516, 2004.

[40] S.-S. Tzeng and F.-Y. Chang, "Electrical resistivity of electroless nickel coated carbon fibers," Thin Solid Films, vol. 388, no. 1-2, pp. 143-149, 2001.

[41] S.-F. Chin, S.-C. Pang, and M. A. Anderson, "Material and electrochemical characterization of tetrapropylammonium manganese oxide thin films as novel electrode materials for electrochemical capacitors," Journal of the Electrochemical Society, vol. 149, no. 4, pp. A379-A384, 2002. 

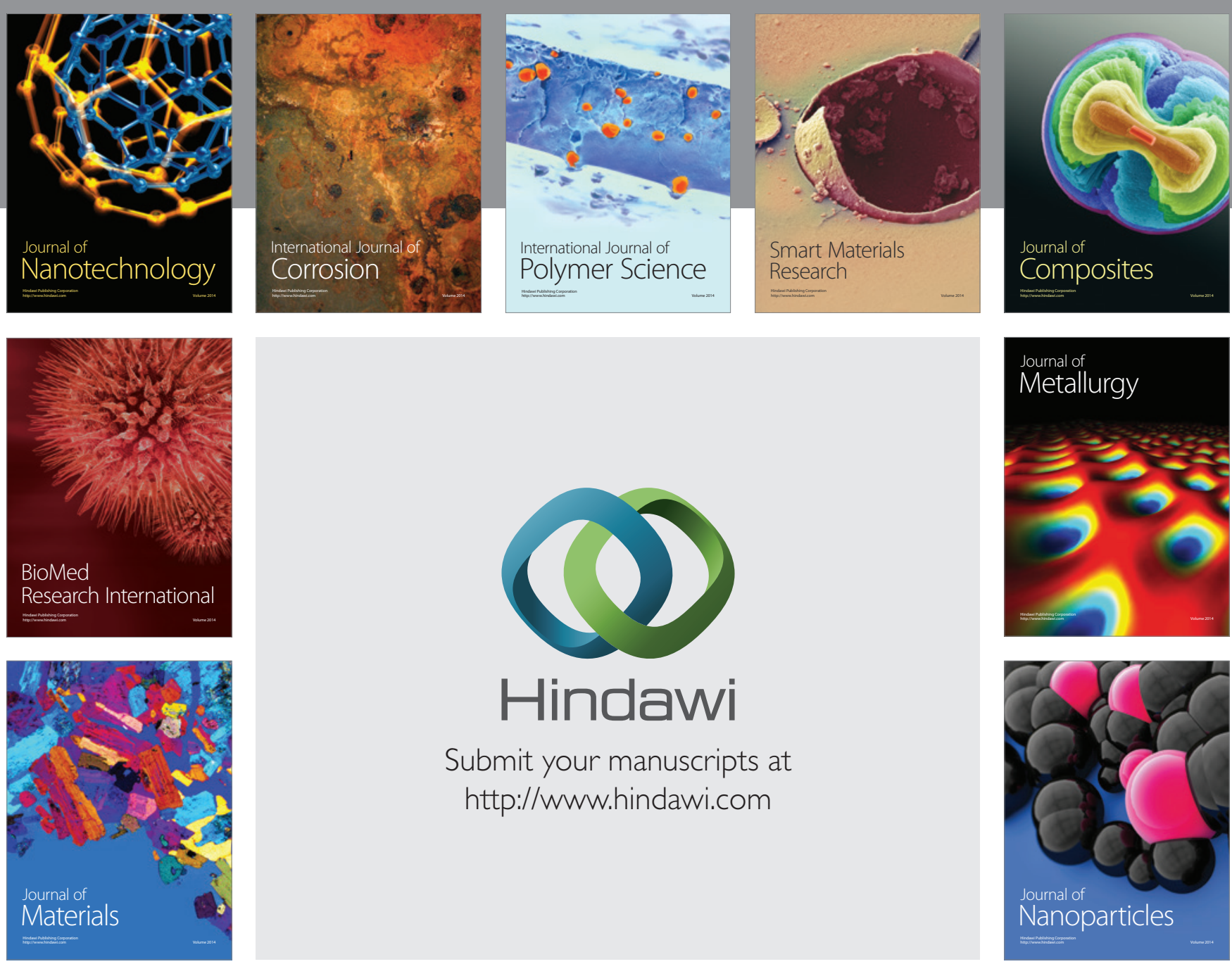

Submit your manuscripts at http://www.hindawi.com
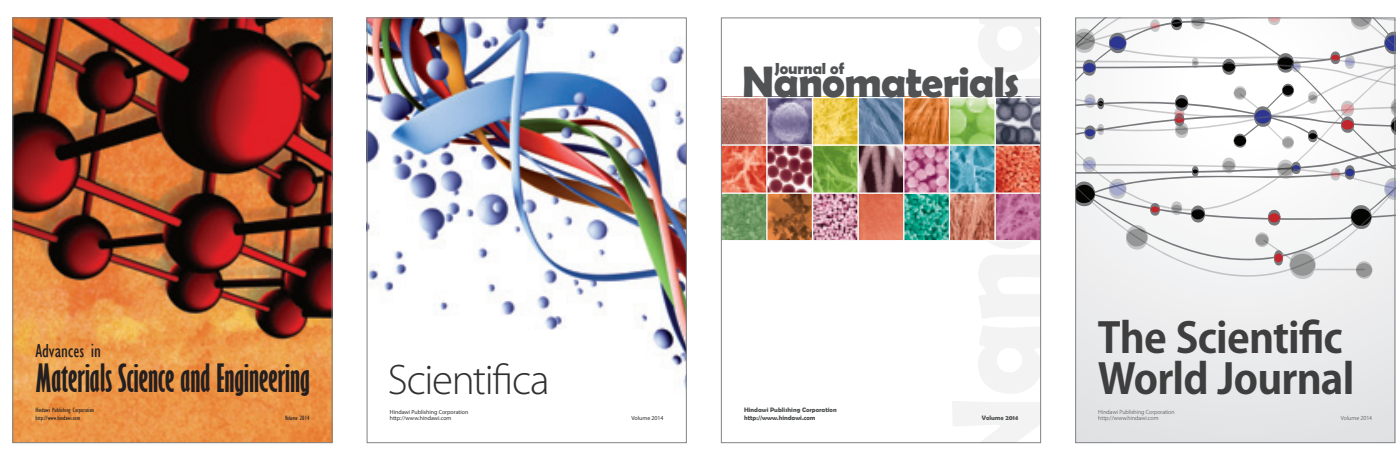

\section{The Scientific World Journal}
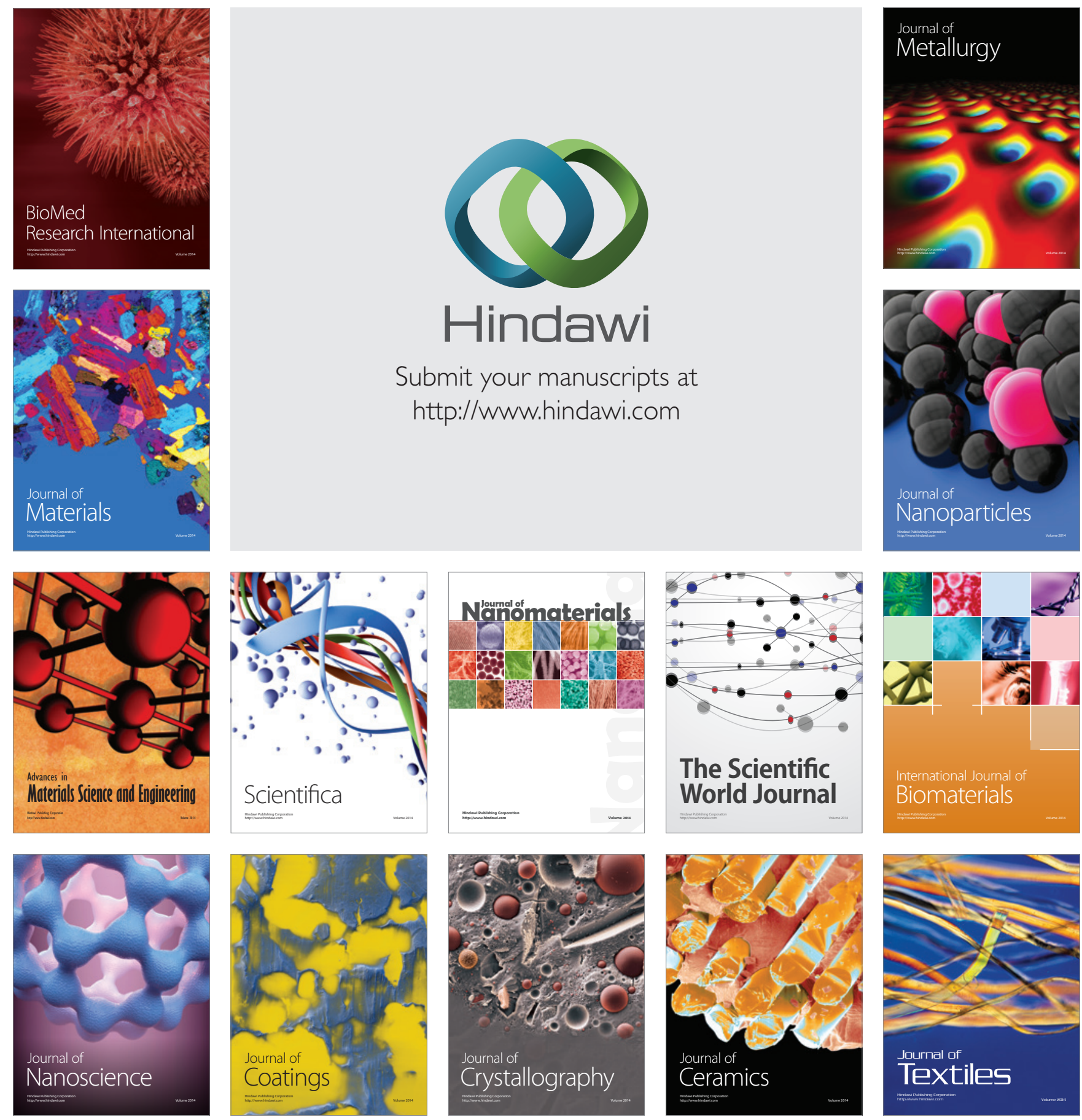